\title{
ENERGY ENGINEERING AND CONSULTING: NEW CHALLENGES AND REALITY
}

\author{
L. D. GITELMAN ${ }^{1}$, V. A. SILBERMANN ${ }^{2}$, M. V. KOZHEVNIKOV ${ }^{1}$, A. Y. MAKAROV ${ }^{1}$ \& D. G. SANDLER ${ }^{1}$ \\ ${ }^{1}$ Ural Federal University, Russia. \\ ${ }^{2}$ Fichtner Consulting Company, Germany.
}

\begin{abstract}
This article presents the results of studies that the authors conducted proceeding from a hypothesis that an increase of crises phenomena in the global economy, uncertainty, and higher risk along with the growing use of digital smart technology apply radically new requirements on knowledge-intensive services in the energy sector. The sector of management consulting and engineering services, which constitute the backbone of knowledge-intensive services, is faced with a new role of providing a mix of services addressing the tasks of devising anticipatory actions amid uncertainty and crisis based on forecasting. Analysis of changes in business models and the content of services indicate their strong capacity for smart logistics of complex projects, knowledge transfer in cooperation with universities and innovation institutions, managing the development of flexible technological and product solutions, and competency development in network teams. This article offers a detailed elaboration of an up-todate conceptual framework of engineering and management consulting; provides an overview of global trends; and presents a case study of collaboration problems that emerge in cross-disciplinary teams working on smart grid projects and projects of energy supply in cities based on smart grid technology. A model of proactive management and anticipatory personnel training in energy companies is proposed. This article describes the skillset needed for implementing a concept of integrated knowledge-intensive services for technological modernization and digitalization of the energy sector.

Keywords: anticipatory training, breakthrough team, engineering, knowledge-intensive services, management consulting, proactive management, smart grid, sustainable energetics, technology modernization.
\end{abstract}

\section{INTRODUCTION}

Until recently, global markets for consulting and engineering services grew steadily. For example, Gartner estimated that the annual growth rate of global consulting market fixed $9.0 \%$ in 2018, reaching 188 billion dollars [1]. The global engineering services market was valued even higher at over 1,000 billion dollars in 2018, with the annual growth rate of $10 \%$ [2].

Some experts noted that these markets enjoyed the second 'golden age' for the industries until 2020 [3]. That 'renaissance of consulting', just like in the postwar years, was due to a torrent of most complex tasks determined by a technology revolution shaking the world. Such radical transformations that are reshaping the manufacturing sector in front of our eyes can be summarized as follows.

1. There is an inflow of innovation that triggers a chain reaction of technological, organizational, and social transformations in various areas of activity and the overall intellectualization of production with a trend toward customization when the consumer gets the product of the desired quality and format.

2. Industry boundaries get blurred and for the newest supra-industrial technologies (digital manufacturing, logistics automation, robotics, materials with adjustable physical and mechanical properties) modular structures are adopted, which constitutes the so-called horizontal knowledge and technology transfer. 
3. The focus of strategic management is shifted toward the timely detection of changes and reduction of the time needed for a systemic response to problem situations. That is why leading consulting companies have been registering a growing interest to instruments improving the agility of management systems.

In these circumstances, digital consulting has proved to be the fastest growing sector, the most highly demanded services being digital maturity assessment and digital presence assessment, a review of technologies and workflow processes in digital channels, construction of a company's digital infrastructure, user interface design, and distance learning tools for personnel training. Leading consulting companies have been rapidly bolstering their digital competence, adopting commencing from 2015 the strategy of taking over small IT companies, start-ups, digital marketing firms, and cybersecurity companies. Demand is growing in the industry for consulting analysts, specialists in databases, forecasting, information security, artificial intelligence, and advanced manufacturing technologies [4].

Such changes will remain a stable trend in the short term in the current unprecedented situation of an economic crisis set-off by simultaneous shocks of different nature - the Covid19 pandemic, transformations in the geopolitical and economic landscape, and a price war between leading oil-producing countries. It is possible to predict with a high degree of accuracy that the consulting industry will see demand for the following services:

- stable business operation and development amid volatile availability of raw materials, workforce, and logistical constraints;

- optimization of resource utilization, higher energy, and environmental efficiency of production;

- supply chain management that takes into account greater market instability;

- arrangement of remote work arrangements; accessibility and performance of the company's information infrastructure.

This article explores the current developments in energy consulting and engineering as the energy sector plays a major role in the economy of individual industries and national security as a whole [5]. No wonder that various restrictions that were introduced during the earlier weeks of the coronavirus pandemic did not affect power engineering much. According to a McKinsey and Company report, as of mid-March 2020, power supply companies along with pharmaceutical companies and telecoms looked like 'safe havens' with an average drop in stock prices of $14 \%$, in sharp contrast to the oil and gas sector (-57\%) and metals and mining $(-34 \%)$. The electric power industry is, nonetheless, bound to face an inevitable decrease (within a range of 5-10\% in various countries) in electric power consumption. This will probably encourage the industry to continue its transition to a service-based business model [6]. Generally, the role and content of engineering and consulting as critical spheres of services in the energy sector are starting to change while their research intensity and the level of digitalization are growing considerably.

\section{BREAKING AWAY FROM TRADITIONAL APPROACHES: A REVIEW OF GLOBAL TRENDS IN CONSULTING}

The fundamental business model of consulting remained unchanged for many years. It employed a specific method of market positioning and creating competitive advantages. Consulting companies sought to convince their customers that their selling point was exclusive 'recipes' that enabled one to create truly effective breakthrough business strategies. The 
customers relied on the brand, reputation, and social status, i.e. the intangible characteristics of the service provider [7].

Currently, this paradigm demonstrates its inadequacy:

1. First and foremost, the consulting industry is to embrace changes in knowledge logistics. The format of consulting projects is changing rapidly toward the adoption of a virtual network model that represents a mix of means and methods: online teams, digital labs, business accelerators, various tools for online social interaction.

New services such as Skype, Zoom, Microsoft Teams, Google Docs, and GoToMeeting make it possible to organize virtual interaction and brainstorming sessions in a global space at near-zero marginal cost. Ultimately, the speed at which ideas are delivered and decisions are made grows explosively.

At the same time, an increasing number of experts from various domains (disciplines) get engaged in projects. This might be a reason why an increasing number of consulting companies have been using the services of freelancers and independent researchers and investing in talent search for those possessing a combination of engineering and economic and engineering and management competencies instead of capital assets $[8,9]$.

Teams of consultants can therefore consist of analysis systems engineers, IT architects, designers, and highly skilled experts in the newest production technology. The quality of communication among them is of utmost importance. There is a point of view pertaining to that: "consulting occurs when knowledge and means are attached to communication in a way that enables activity that is otherwise impossible within the framework of traditional organizational structure' [10].

Consulting companies are starting to actively adopt new organizational structures that reject the traditional pyramid model and are instead built either on the 'diamond' model consisting of a leader, experienced experts on specific issues, virtual teams, and freelancers, or on the so-called model of 'flat hierarchy', in which consultants, regardless of their area of expertise, qualification, or even experience, have equal status yet they can be team leaders depending on the features of the project.

2. There is a growing interest to projects aimed at fine-tuning management systems through change: large participants in various markets consider flexibility to be the key to leadership. In that regard, consulting companies will have to move over to an integrated consulting methodology that prioritizes the provision of tool support for preemptive actions, anticipatory learning, development of production solutions with a good potential. Such methodology is combined with interdisciplinary research. Moreover, consulting companies consider it extremely important to maintain a start-up culture: it is impossible to continue to exist as a hierarchical structure and to teach customers how to adopt Agile at the same time.

3. The need is growing for scientific research and project development at the intersection of science, education, engineering, and management that create interdisciplinary tools for designing and introducing technologies of the future. Consulting, especially management consulting and engineering and technical consulting have been increasingly taking on these roles. For example, Pantic-Dragisic and Söderlund [11] posited that the significance of technology and engineering consulting is bound to grow as this particular segment boasts the largest concentration of 'brainpower' - an extremely scarce and costly resource even for large corporations.

4. Boosting innovation (and, as a result, research, forecasting, and analysis) is becoming the most important goal for management and technology and engineering consulting [11, 12]. 
By focusing on these areas of activity, the customer can create unique knowledge that forms the foundation for the key competences of their business that increasingly determine their competitive edge in the long run. It has to be noted that, in a condition of uncertainty, the key competences must evolve in anticipation of changes in the marketplace. It is by continuously generating new knowledge coupled with a strategy building process and its application in planning, production, logistics, and marketing, so that the business gets the opportunity to prepare the ground for rapid reconfiguration of its key competences.

5. The share of big engineering projects that are aimed at modernizing existing production and management systems is decreasing, while the share is growing of modular and more localized projects of designing completely new systems based on cloud technologies, artificial intelligence, agile business processes, and smart production.

Additionally, consulting companies themselves are becoming analytical platforms that make it possible to mitigate market uncertainty by using predictive analytics systems. For example, Pang et al. [13] suggested a model for integrating consulting services into an electricity market with active consumer participation. Such a market features owners of small-scale renewable energy installations who can trade electric power between themselves without a system operator. Such market participants pose a certain risk to the stability of the energy system as the volume of transactions between them is unpredictable and de facto uncontrollable. In this case, consulting services perform a control and forecasting function with regard to (a) potential demand for electricity and capacity; (b) potential and actual power and load flows; (c) investment in the retrofitting of power grids; and (d) optimal tariffs and penalty fees for exceeding transaction limits for certain categories of consumers.

Summing it up, it should be said that the emphasis in change management is shifting toward prevention of problems. Consultants are tasked with preparation of management systems and information support infrastructure which would use market forecasts, identification of technology trends and changes in the consumer preference structure as the basis for self-organization, and anticipatory decision-making concerning business development.

\section{GLOSSARY MATTERS}

We shall begin with defining the trending subjects of consulting and engineering - technological modernization and industry of the future. The authors define technological modernization as a radical overhaul of the apparatus of production on the basis of the latest developments in science and technology as well as systemic organizational transformations.

In parallel with technological modernization, there emerges the industry of the future (Industry 4.0) - an industrial environment that is intelligent and saturated with various information and communications technologies and systems of measurement. Naturally, it will be possible to see an intensive convergence of the achievements of the new industry and technological modernization in the near future.

The authors interpreted engineering as an organizational technology that provides for the execution of some phases of innovation: pre-project development, feasibility studies, development, supply of equipment, personnel training, turnkey delivery, and service support. Essentially, this means designing, building, and managing the life cycle of a system. That is why current engineering companies are diversified structures which seek to act as the systems integrator in project management.

According to the segmentation introduced by FEACO, engineering, i.e. engineering consulting belongs to the sector of consulting services [14]. All sorts of the definitions and 
classifications of consulting can be found in the literature [15-17]. For the purposes of this study, it is important to emphasize the following aspects:

1. Consulting is an intellectually demanding area of highly professional services in the field of production and management systems improvement for the industry in the future. The subject of consulting does not have an established knowledge system yet. That is why, when addressing such complex tasks, consulting should draw on a specific methodology that represents an approach to selecting knowledge and methods of designing new organizational systems and arranging collaborative innovation work. There appears the need to create combinations of systems of various types (management, engineering, information, and sociocultural ones), i.e. the need for system integration of dispersed projects that are essentially a set of tasks, which are solved with various poorly coordinated means and methods.

2. The methodology itself is improved though the implementation of highly specific activity that is tightly coupled with research and forecasting. This adds to the importance of methodological literacy, the thinking style, and the capacity for transformative engagement in any highly professional sphere that is related to the industry in the future and in the field of knowledge-intensive services in particular.

3. Consultants increasingly employ a heuristically approach to solution searching, constantly adjusting their strategies on the basis of the feedback from stakeholders. Several important conclusions can be drawn from this point: (a) consultants have to have their own concept of solving the problem of complex system improvement (their know-how) and (b) they should view the concept as a broad sketch that can be tweaked in the course of the concept implementation.

The work of consultants, therefore, becomes intellectually more complex and mandates constant competency development which is impossible without continuous learning, intense thinking, and communication with many experts.

Speaking of technological modernization and the industry of the future as promising domains for consulting services, the authors suggested a new definition that describes the peculiarities and requirements set out earlier.

Integrated consulting for anticipatory development (ICAD) refers to the method, structure, and activity of providing particularly complex and highly qualified services based on systematic mix of knowledge and methodologies for addressing future challenges. This mix is built on studies of trends and scientific and technological developments in the global environment, anticipatory learning programs, methods of cooperative creation of new knowledge, and innovation in adjacent areas - management, engineering, information, sociocultural and socio-technological ones (Fig. 1). An essential prerequisite and precondition for ICAD is the network model of collaboration among regional, national, and international experts who work together on one task as one team.

\section{CURRENT TRENDS IN CONSULTING SERVICES AND ENGINEERING IN THE ENERGY SECTOR}

According to [18], the market for energy engineering and consulting is expected to grow by $45 \%$ and 20\%, respectively, by 2025, as compared with 2019 levels. Considering today's situation, these forecasts need to be reviewed. However, certain industry-specific factors of long-lasting nature will determine an increased significance of consulting services in the energy sector. These include: 


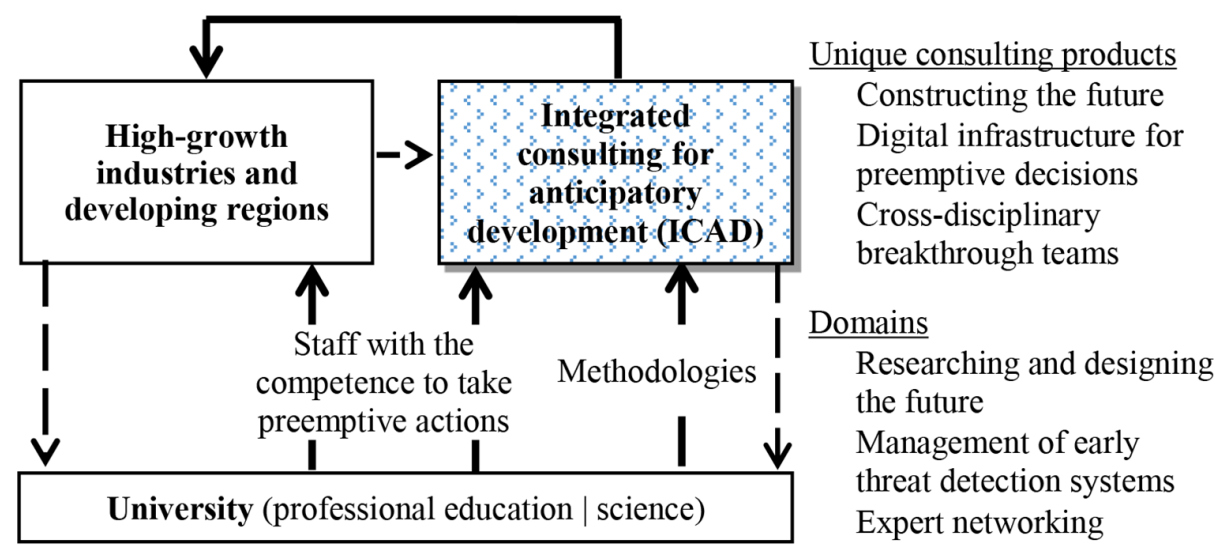

$\longrightarrow \longrightarrow$ Feedback (transfer of best practices and engagement of branch experts)

Figure 1: Integrated consulting for anticipatory development in action.

- general adoption of digital technologies that allow for new approaches to production process and energy asset management and drive the emergence of a new market architecture, in which the energy consumer becomes an active participant who performs trading operations independently;

- decentralization of the energy sector that shows in the development of small-scale generation and microgrids and its convergence with other critical infrastructure sectors (natural gas and water supply, telecommunications, government services), thus stipulating the creation of an appropriate legal framework;

- prices of energy commodities are highly volatile, undermining the stability of the investment process and tariff policy;

- accelerated decarbonization and rapid spread of environmentally friendly power-generating installations;

- maximum encouragement of energy consumption and, at the same time, implementation of demand side management programs that make it possible to prepare in advance for a new phase of electrification $[18,19]$.

The emergence and development of smart grids in various countries is one of the new areas where energy consulting and engineering are particularly important [20,21]. The appearance of such grids was a result of digital technology advancements as well as changes occurring in the structure of electrical and thermal energy production. The changes are associated with a growing transition to renewable energy sources, primarily solar energy and wind power, and a shift away from conventional energy carriers, such as coal, gas, and nuclear power. For example, the energy concept of the German Federal Government that was published in September 2010 states that renewable energies should account for $60 \%$ of gross electricity production by 2050, up from today's $9-11 \%$ [20]. The liberalization of the electricity market played an important role in the emergence of smart grids because, as a result of the unbundling of the natural albeit regulated monopoly, the generation, transmission, and energy distributions (primarily distribution of electricity) were separated, and the end consumer is now able to choose who to buy electricity from. This not only resulted in the transformation of the traditional structure of electricity supply (Fig. 2) but also led to the development and 


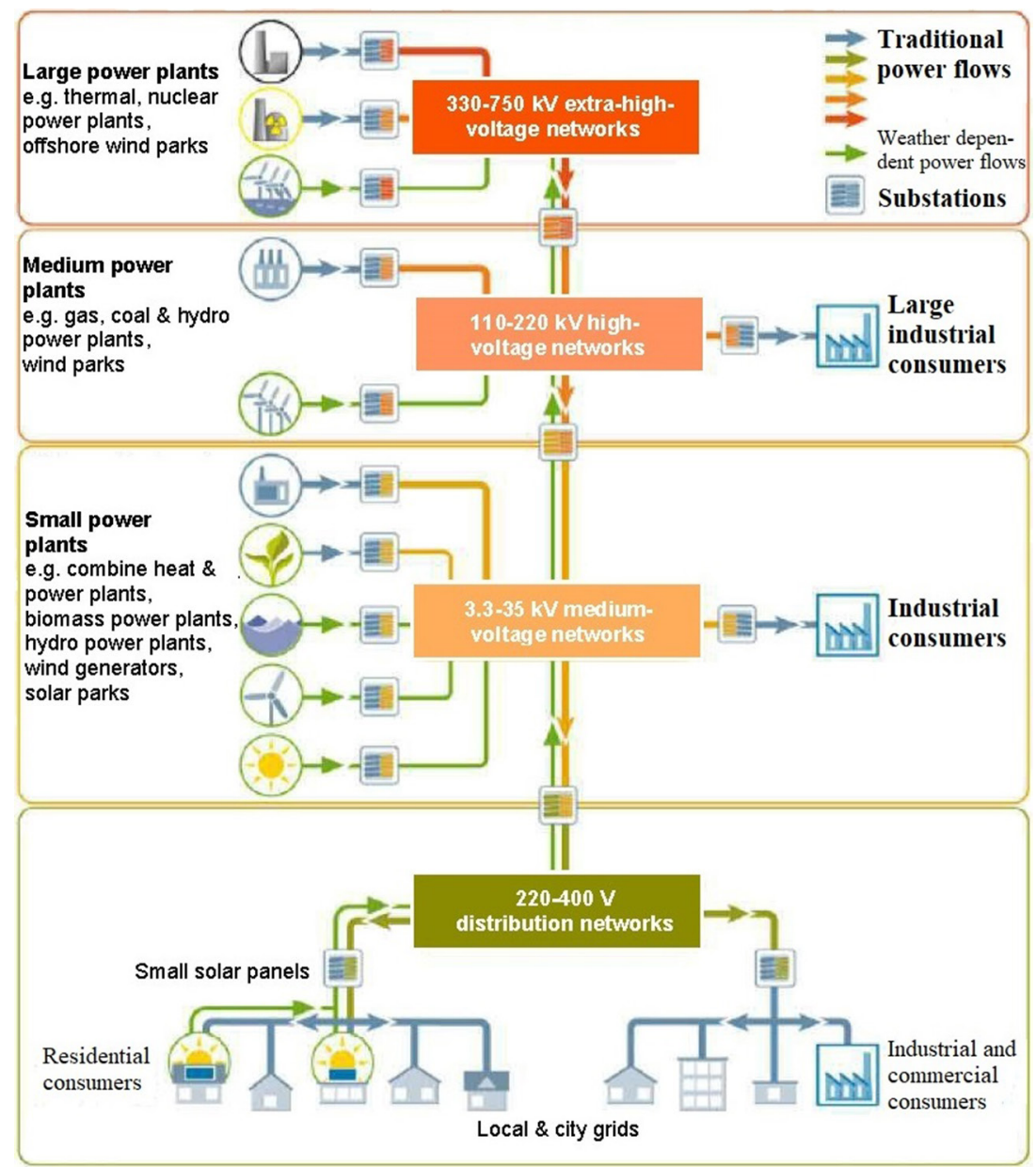

Figure 2: Traditional structure of electricity generation, transmission, and distribution.

installation of new communication channels and interface devices for real-time data exchange between new participants - those who produce and those who transport energy - who naturally appear on this market (Fig. 3).

By comparing Figs 2 and 3, one can see that a peculiarity of smart grids is the availability of advanced IT infrastructure (IT networks) that operates in parallel with the existing power networks (ideally with all voltages grids) [20]. This IT network is usually built on dedicated telephone lines or radio frequencies. Information can also be transmitted and received via transmission lines after their appropriate modifications (PLC-channels, OPGW-channels, etc.). This IT network is connected to compatible measuring and control devices and regulators ('smart' actors) that are installed at all facilities that are connected to electric power networks. The devices transmit and receive measurement data and regulatory and control commands.

It is important that transmission and reception of the signals in smart grids is carried out in a real-time mode, thus improving the balance of generated and consumed capacity through full utilization of the reserves of static stability margin in the grid. This makes it possible to 


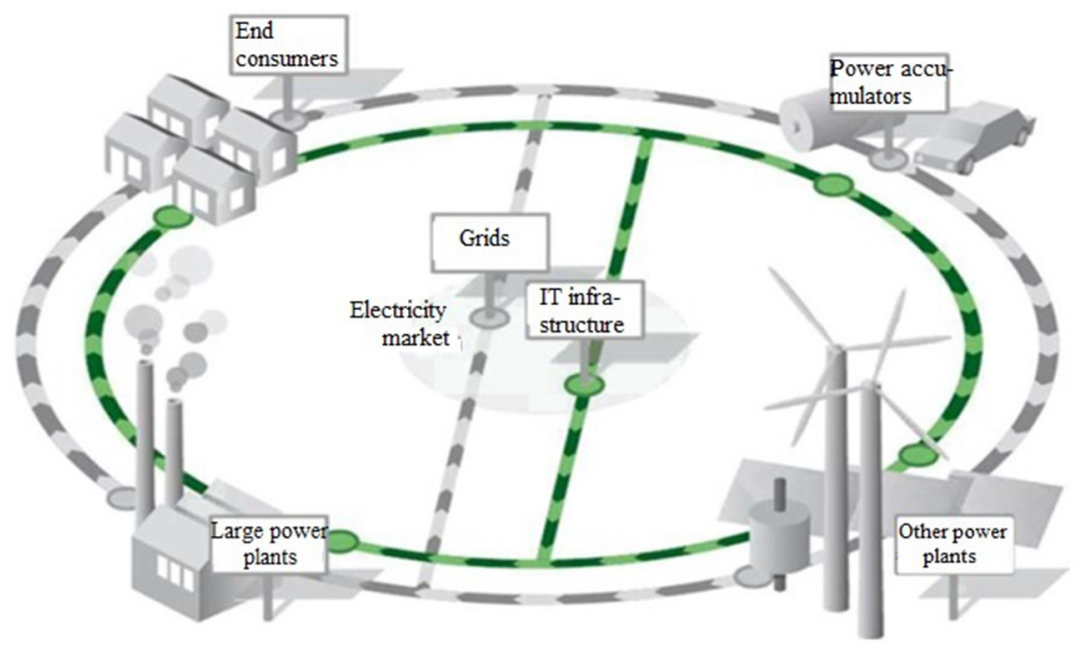

Figure 3: Layout of 'smart' grid structure.

transmit capacity from the power plant to consumers via existing networks without building additional lines. In other words, it is the load that actually and precisely controls the electric output required for such load. Using renewal energy installations for generating electric power makes it possible to follow the load change, that is, to adjust the capacity of associated wind parks and solar power plants practically instantly. This is an advantage over conventional highly inertia power generation technologies (heavy duty steam and hydro generators).

Konrad and Scheer [20] attributed setbacks in the development of smart grids to socio-technical factors that depend not only on the level of technological development (availability of the necessary 'smart' products from the sectors of IT, communications, and data processing systems) but also on public awareness of the need to adopt this technology and of society's role in this process. This lack of awareness primarily stems from vaguely formulated key tasks for new participants who appeared on the market as a result of its liberalization. The ranks of market participants are filled even with individual households who, due to market liberalization, have the opportunity to buy electricity from any producer, even those hundreds of kilometers away. It is not always possible to convince such households to invest in rather costly 'smart' products and development of communication networks.

This is where independent consulting will operate, identifying the optimum spots for the installation of 'smart' products by the energy producers and various consumers (including end consumers) of electricity and thermal energy and determining the optimal distribution of investments that are needed for the creation of smart grids between them. It is energy consulting providers who are capable of assessing the reliability of the IT network and the security of consumer data that are constantly exchanged within the network. Additionally, energy consulting providers could propose appropriate amendments to legislation, draft new standards for smart girds, and design various tariff options that would fit the new system of energy flow management, thus stimulating the development of smart grids. This is, however, 'a terra incognita' for current consulting companies. 


\section{RESULTS AND DISCUSSION}

The authors' experience of building consulting support systems for complex projects of technological modernization and digitalization in the energy sector was described in a series of published works (e.g. [22, 23]). In this article, the focus is on the operability of the smart partnership of science, education, and business as an integral system.

1. The role of the competence center, integrator, and methodologist of the smart partnership is performed by the Research and Educational Centre for Interdisciplinary Investigations and Educational Programs in Hi-Tech Industries (REC ENGEC) at Ural Federal University (Fig. 4).

2. To implement theoretical and methodological concepts, there was designed a program called 'new leaders for a technological modernization and the industry of the future', a technological platform for anticipatory learning [24], and a model of a business school 2.0 that puts into practice the above ideas.

3. A portfolio of anticipatory development consulting projects which has been brought to the market has multiple purposes: ramping up innovation in business; synchronizing innovation processes with human resource development and the nurturing of talent;

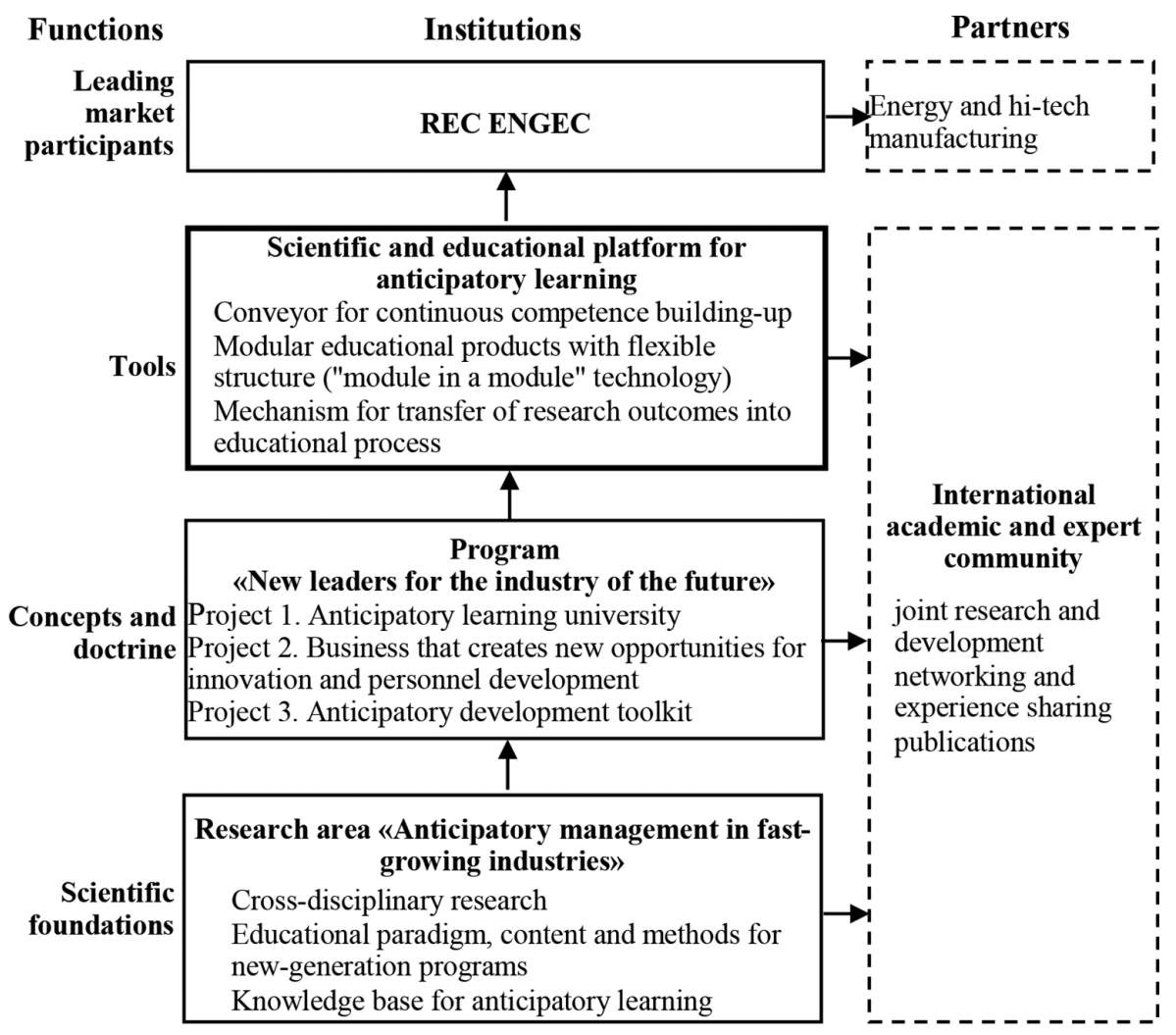

Figure 4: Integration of research, educational, consulting, and innovation within smart partnership. 
and enforcing the mechanisms of the smart partnership of university and business. It is foreseen that projects can be implemented as part of one package or as modules. In the latter case, each model contributes to the customer's value chain, which is in line with a progressive business model of a new generation of management consulting services.

The cited consulting projects were successfully completed at large Russian energy companies (MRSK Ural, T Plus, Bashkirenergo, Bashkir Grid Company) and at Ural Federal University.

The implementation of educational programs that are aimed at breaking down the established stereotypes and patterns and making a quick shift to new tasks, goals, means, and mechanisms of achieving them can be roughly divided into four blocks that can be implemented in parallel or consecutively.

Teaching management to change the business paradigm; forging a new mentality - from vertical integration to cross-functional cooperation. Energy companies, including Russian ones, traditionally boast strong teams of technical professionals whose mission is to ensure the operational reliability of equipment, usually without analyzing the needs of the customer and the market. As a new social and economic reality is taking shape, accomplished professionals who have a degree in energy technology need to receive training in the related competences of management and business. Building up cross-disciplinary knowledge and approaches to management enabled the leadership of the companies to become mentally prepared to deal with the challenge of making the transition to modern methods of production process management in companies. Since 2000, REC ENGEC has delivered training to hundreds of top managers and energy company employees on how to nurture cross-functional mentality [9].

It is important to note that building a core team of cross-functional professionals is an essential but insufficient condition for forming breakthrough teams in companies.

Building a breakthrough team is essentially a complex management process that requires that two conflicting tasks be accomplished in an actual production situation: on the one hand, the integrity, reliability, and controllability of the production process must be maintained. On the other hand, revolutionary transformations need to be carried out in collaboration with all structures to achieve a transition from a horizontal to vertical integration and establish endto-end business processes. Horizontally integrated end-to-end business processes blur (but do not destroy) the borderline between various functional areas and the vertical hierarchy of management, usually cutting down the number of the tiers of management within the company. This task calls for new recruitment approaches and a talent search at all levels of the management pyramid. Another paradox of the process is that it would be ineffective without the active involvement of the chief executive officer and key top managers, while the prime driving power is middle managers who are more active and ambitious. Here is a simple formula of breakthrough team effectiveness: it should consist of members with equal rights, regardless of their status in operating activities. The chief operating officer stands out from the team as it acts not only as the customer, but also as a project participant (at least conceptually).

Transition to horizontal ties between administrative and technological processes. As a result of the traditional approach to managing a company with a multitiered management system and vertically integrated architecture, functional divisions generate isolated information flows that are not accessible to colleagues from other departments. All too often, this results in 
cross-functional cooperation existing only at the top management level and cross-functional decisions typically being made by the chief executive officer only. As an outcome, responsibility levels drop in managerial personnel, responsibility is shifted onto the shoulders of superiors (those who make decisions are accountable), and the entire management process slows down tremendously. That is why companies need to embrace horizontal management and authority must be delegated to managers who control processes in a particular point of business. Companies that have adopted end-to-end business processes have substantially reduced the time required for making a decision and improved the quality of decisions [24].

Hiring external consultants to address the tasks of technological modernization. One of the authors of this article worked as the CEO of Bashkirenergo, CEO and chair of the board of Bashkir Grid Company. Those jobs enabled him to apply the above ideas in practice when implementing projects of Smart Grid [25] and automated end-to-end business processes [26] at the Bashkir Grid Company. Although the field work phase of the Smart Grid project did not begin until 2014, the process of the transformation of managers' mentality, construction of cross-functional thinking, and preparedness for a transition to a horizontal communication mode started in 2011 when executives with technology backgrounds were dispatched to Ural Federal University to receive training in management and economics of production. At the same time, projects teams were formed of the most proactive and talented persons from all levels of management in the company.

Without an experience of its own, the company hired a large number of external consultants for direct or indirect participation in the preparatory phase of the project. Among the contractors were market giants such as Siemens, Israel Electric, Ural Federal University as well as small companies with one competence, yet critical and extremely useful. It was the external consultants who helped the company form a vision of strategic development. It has to be emphasized that the consultants assisted only the managers in their work because when the management seeks to evade their direct duty of forming a strategy and tries to delegate it completely to consultants, the process ends in a deadlock.

The efforts of the Bashkirenergo managers with the help and experience of external consultants, who joined the project teams, made it possible to increase labor productivity in the company by $15 \%$ within a period of 5 years, reduce transmission losses by $30 \%$, and increase the grid reliability proportionally. It should be noted that the grid business is naturally conservative and it is not prone to internal changes. It was the formation of task-based cross-functional competences of the consulting team and the engagement of expert from the fields of business, science, and personnel training that the desired result was achieved.

This particular approach can take university consulting services to a new level, enabling universities to become a coordination platform for breakthrough changes in the economy, industry, and business.

\section{CONCLUSION}

This study has shown that the consulting industry is facing groundbreaking transformations as regards business models, approaches to customer service, and key competencies. The top current issues that energy consulting services and engineering need to deal with are a switchover to cutting-edge production technologies, smart grid deployment, creation of models of relationship with active consumers, and anticipatory training for personnel and breakthrough teams for engagement in technological modernization and digitalization projects. It is obvious that in the existing circumstances consulting becomes the intellectual integrator of the processes of the energy sector's transition to a new paradigm. 
In this regard, the introduction of the concept of ICAD enables a radical transformation of the methodology of consulting services that specialize in facilitating the adoption of anticipatory development management systems by customers amid uncertainty. The new value of consulting services for customers is ensured by the fact that the overall goal of the methodology is to preemptively identify threats and new opportunities, thus getting exclusive advantages for competitive performance in the future; experts from various professional domains (science, education, and consulting) are engaged and a wide scope of problems is covered, which guarantees the objectivity and the breakthrough nature of proposed solutions; and support can be provided throughout the project life cycle and with the delivery of modular products.

The authors' experience shows that a consulting methodology can be developed and enriched through the simultaneous invigoration of innovation and transformation both in energy companies and universities: they need to change their education paradigm and adopt anticipatory training programs, nurture a new generation of leaders who have competences for preemptive action, and create and bolster a specialized contour of the research and methods of design in the future.

\section{ACKNOWLEDGMENT}

The work was supported by Act 211 of the Government of the Russian Federation, contract No. 02.A03.21.0006.

\section{REFERENCES}

[1] Healey, C., Williams, B., Sullivan, P. \& Blackmore, D., Market share analysis: consulting services. https://www.gartner.com/en/documents/3907120/market-share-analysisconsulting-services-worldwide-2018. Accessed on: 28 April 2020.

[2] Engineering Services Global Market Report 2020. https://www.thebusinessresearchcompany.com/report/engineering-services-global-market-report. Accessed on: 28 April 2020.

[3] Vitaud, L., Consulting will never be the same again. https://medium.com/want-morework/consulting-will-never-be-the-same-again-210bc3e37951. Accessed on: 28 April 2020.

[4] Cecere, M., The future of consulting through 2020. Digital is changing the operating model, services and strategies of consulting firms. https://www.prodyna.com/ documents/10195/1650832/The+Future+Of+Consulting+Through+2020.pdf/ b929e2f2-bccd-474b-a16a-9f8fe3ae8271. Accessed on: 28 April 2020.

[5] Gitelman, L.D., Gitelman, L.M. \& Kozhevnikov, M.V., Window of opportunity for sustainable energy. International Journal of Energy Production and Management, 2(2), pp. 173-185, 2017.

[6] Kozhevnikov, M., Approaches to the formation of energy service markets in developing countries. WIT Transactions on Ecology and the Environment, 190(1), pp. 27-36, 2014.

[7] Cole, D., The future of consulting: thoughts on how the industry should evolve. https:// www.linkedin.com/pulse/future-consulting-thoughts-how-industry-should-evolvedouglas-cole. Accessed on: 28 April 2020.

[8] The consulting firm of the future. http://edenmccallum.com/pdfs/Consulting_Firm _ of_the_Future_2013.pdf. Accessed on: 28 April 2020.

[9] Gitelman, L., Kozhevnikov, M. \& Ryzhuk, O., Advance management education for power-engineering and industry of the future. Sustainability, 11, 5930, 2019. 
[10] Andler, N., Tools for Project Management, Workshops and Consulting: A Must-Have Compendium of Essential Tools and Techniques, Erlangen: Publicis Publishing, 2008.

[11] Pantic-Dragisic, S. \& Söderlund, J., Swift transition and knowledge cycling: Key capabilities for successful technical and engineering consulting? Research Policy, 49(1), 130880, 2020.

[12] Dougherty, M., Boom times for technocrats? How environmental consulting companies shape mining governance. The Extractive Industries and Society, 6(2), pp. 443-453, 2019.

[13] Pang, Y., He, Y. \& Cai, H., Business model of distributed photovoltaic energy integrating investment and consulting services in China. Journal of Cleaner Production, 218, pp. 943-965, 2019.

[14] Survey of the European Management Consultancy, http://www.feaco.org/sites/ default/files/sitepagefiles/Feaco.Survey\%202017-2018.pdf. Accessed on: 28 April 2020.

[15] Greiner, L. \& Poulfelt, F., Handbook of Management Consulting - The Contemporary Consultant: Insights from World Experts, Mason: Thomson South-Western, 2005, 393 p.

[16] Jang, Y. \& Lee, J., Factors influencing the success of management consulting projects. International Journal of Project Management, 16(2), pp. 67-72, 1998.

[17] Lahti, R.K. \& Beyerlein, M.M., Knowledge transfer and management consulting: A look at "The firm". Business Horizons, 43(1), pp. 65-74, 2000.

[18] Berger, R., Energy efficiency services in Europe. Tapping into a powerful market, https://www.rolandberger.com/en/Publications/Energy-efficiency-services-a-key-market-in-the-European-industrial-landscape.html. Accessed on: 28 April 2020.

[19] Power Market Study 2030. A new outlook for the energy industry. https://www2. deloitte.com/content/dam/Deloitte/de/Documents/energy-resources/Deloitte-PowerMarket-Study-2030-EN.pdf. Accessed on: 28 April 2020.

[20] Konrad, W. \& Scheer, D., The smart grid from societal visions - InnoSmart work report 02. Environment and societal accepted transformation of energy systems, Stuttgart: SÖF; foster registration 03EK3515. 45 p. (in German).

[21] Cescolini, F., Smart Grids (in German), https://www.net.in.tum.de/fileadmin/TUM/NET/ NET-2011-07-2/NET-2011-07-2_15.pdf. Accessed on: 28 April 2020.

[22] Gitelman, L. \& Kozhevnikov, M., New leaders for technological breakthroughs in the energy industry. WIT Transactions on Ecology and the Environment, 224, pp. 499-511, 2017.

[23] Gitelman, L.D., Kozhevnikov, M.V. \& Sandler, D.G., Technology platforms as a tool for solving complex innovation problems. International Journal of Design \& Nature and Ecodynamics, 11(4), pp. 584-592, 2016.

[24] Chang, C.M., Service Systems Management and Engineering: Creating Strategic Differentiation and Operational Excellence. Hoboken, New Jersey: John Wiley and Sons, 2010.

[25] Makarov, A.Y., Power Grid Digitalization. Practical Experience. Moscow: Ekonomika, 128 pp, 2019.

[26] Makarov, A.Y., Radygin, Y.A., Sharafieva, G.A. \& Rostik, O.M., Power grid infrastructure modernization by the implementation of smart grid technologies. Challenges and Solutions in the Russian Energy Sector, ed. S. Syngellakis \& C. Brebbia, Springer: Cham, pp. 81-88, 2018. 